\title{
Evolução tectônica da Zona de Cisalhamento Caxambu, MG
}

\author{
Camilo Correia Trouw ${ }^{1}$, Felipe Fernandes Fonseca de Medeiros ${ }^{1} \&$ \\ Rudolph Allard Johannes Trouw ${ }^{I}$
}

\begin{abstract}
Resumo A Zona de Cisalhamento Caxambu (ZCC), de direção NE-SW, é um exemplo de um conjunto de zonas de cisalhamento com atitude semelhante que representam a atuação final da tectônica neoproterozóica ligada à Orogenia Brasiliana na região do sul de Minas Gerais e Rio de Janeiro. Trata-se de uma zona de cisalhamento com comportamento predominantemente dúctil que afeta rochas metaígneas e metassedimentares. As primeiras constituem o embasamento paleoproterozóico e os metassedimentos fazem parte da Megasseqüência Andrelândia (MSA) de idade neoproterozóica. $\mathrm{Na}$ área estudada foram reconhecidas seis unidades de mapeamento: ortognaisse (embasamento), biotita gnaisse bandado (MSA), quartzito (MSA), biotita xisto (MSA), granada-muscovita xisto (MSA) e um plug de rochas alcalinas, de provável idade cretácea. Na região ocorrem dois conjuntos principais de estruturas: a fase $\mathrm{D}_{\mathrm{B}}$ gerou a foliação principal com lineação associada, ambas relacionadas a formação de nappes com transporte tectônico para leste, ligadas à Faixa Brasília. O outro conjunto, associado à Faixa Ribeira, inclui dobras e empurrões com vergência para NW e foi atribuído à fase $D_{R}$. Nos estágios finais desta fase foi gerada a Zona de Cisalhamento Caxambu em um regime de compressão E-W. A ZCC se estende por mais de $100 \mathrm{~km}$, com largura variável, em torno de $2,5 \mathrm{~km}$, e tem um deslocamento destro horizontal estimado na área estudada em $14,5 \mathrm{~km}$. Incluindo estimativas já publicadas de áreas adjacentes obteve-se um valor médio para este deslocamento de 17,6 km, resultando num valor médio para $\gamma$ de cisalhamento simples em torno de sete. Associadas à ZCC ocorrem rochas miloníticas contendo os seguintes indicadores cinemáticos: minerais alongados assimetricamente, foliação oblíqua, estruturas $\mathrm{S}-\mathrm{C}$, porfiroclastos manteados, microfalhas e microdobras assimétricas. As condições metamórficas durante a milonitização são estimadas como início da fácies anfibolito.
\end{abstract}

Palavras-chave: zona de cisalhamento, milonitos, Megasseqüência Andrelândia, Caxambu.

\begin{abstract}
Tectonic evolution of the Caxambu shear zone. The NE-SW trending Caxambu Shear Zone (CSZ) is an example of a group of similar shear zones that crop out in southern Minas Gerais and adjacent Rio de Janeiro states. They represent the final stage of the Neoproterozoic tectonic activity related to the Brasiliano Orogeny in this region. It is a dextral shear zone with predominantly ductile behavior. The CSZ affects metaigneous and metasedimentary rocks of a Paleoproterozoic basement with its Neoproterozoic cover denominated Andrelândia Megasequence (AMS). Six mapping units were recognized: orthogneiss (basement), banded biotite gneiss (AMS), quartzite (AMS), biotite schist (AMS), garnet muscovite schist (AMS) and a plug of alkaline intrusive rocks of probable Cretaceous age. Two groups of structures were recognized in the area. The first group, attributed to deformation phase $\mathrm{D}_{\mathrm{B}}$, related to the Brasília Belt, includes the main foliation and associated lineation and extensive nappe structures with tectonic transport top to the east. The second group, related to the Ribeira Belt and labeled $D_{R}$, includes the Caxambu Shear Zone. The CSZ is more then $100 \mathrm{~km}$ long and about $2.5 \mathrm{~km}$ wide; its dextral horizontal displacement in the studied area is estimated at about 14.5 $\mathrm{km}$. Including published estimates from adjacent areas an average value of $17.6 \mathrm{~km}$ is obtained, resulting in an approximate average value for $\gamma$ of simple shear of seven. Associated to the CSZ mylonitic rocks were formed containing the following shear sense indicators: mica fish and other minerals with similar shape and asymmetry, oblique foliation, S-C structures, mantled porphyroclasts and asymmetric microfolds. The metamorphic conditions during mylonitization are estimated at lower amphibolite facies.
\end{abstract}

Keywords: shear zone, mylonites, Andrelândia Megasequence, Caxambu.

INTRODUÇÃO A Zona de Cisalhamento Caxambu (ZCC) faz parte de um conjunto de zonas de cisalhamento que possuem atitudes íngremes a subverticais e direções NE-SW. Estas ocorrem ao sul e a sudeste do Cráton de São Francisco, principalmente nos estados de Minas Gerais e Rio de Janeiro. Este conjunto de zonas de cisalhamento é classificado como "Cinturão Transcorrente Paraíba do Sul" por Ebert et al. (1996). Predominam zonas de cisalhamento de movimentação destra (Fig.1). Estudos anteriores (e.g. Almeida 2000) descrevem tais estruturas, porém não destacam o fato de existir uma quantidade significativa de zonas de ci- 


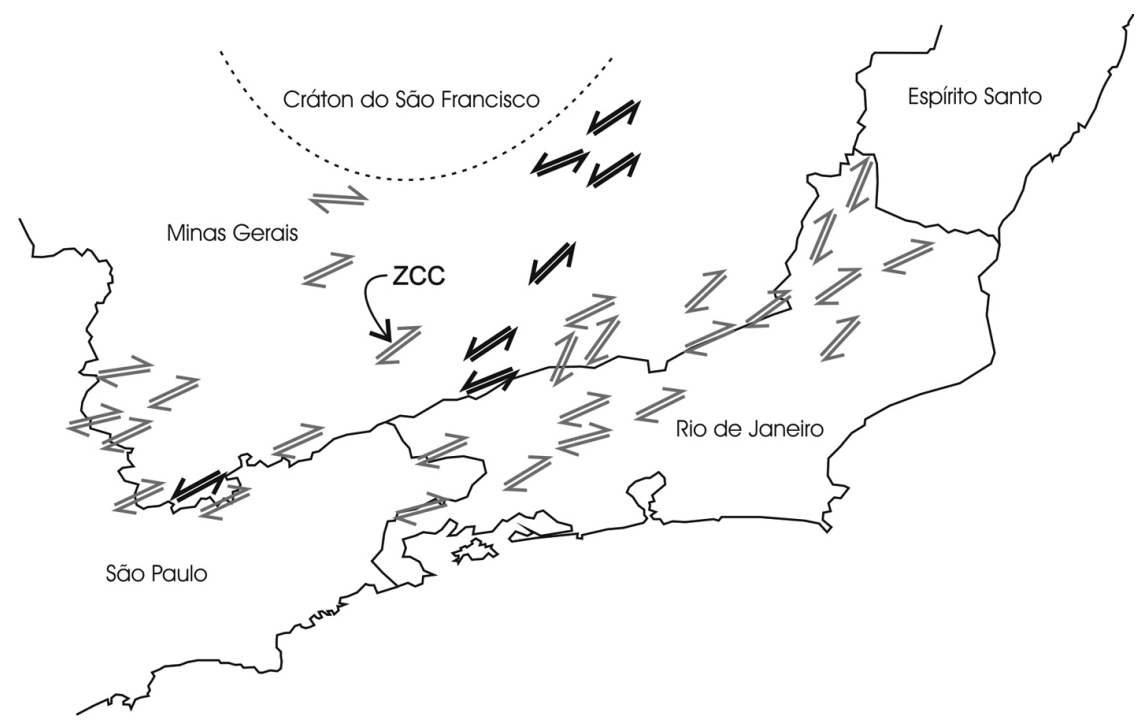

Figura 1 - Mapa de sentido de movimento em zonas de cisalhamento relacionadas à parte central da Faixa Ribeira. Destro (cinza) e sinistro (preto) (baseado em Silva 2001 e COMIG 2003).

salhamento com sentido de cisalhamento sinistro, oposto ao principal.

A deformação responsável por estas estruturas reporta aos estágios relativamente tardios da tectônica relacionada à Orogenia Brasiliana (Almeida et al. 1975, Campanha 1981, Machado \& Endo 1993a,b,c, Almeida 2000, Heilbron et al. 2004). O significado destas zonas na Faixa Ribeira foi interpretado de maneiras diversas, desde um papel preponderante num orógeno transpressional (Machado \& Endo 1993a,b,c), passando por um modelo de indentação (Vauchez et al. 1994), até um papel secundário nos ajustes finais do orógeno (Almeida 2000, Heilbron et al. 2004). Neste contexto, o presente trabalho pretende contribuir com dados de campo e petrográficos sobre uma destas zonas.

A ZCC é uma zona de cisalhamento predominantemente dúctil com movimento destro que apresenta também escassos indicadores cinemáticos com sentido de cisalhamento sinistro. Foram reconhecidas estruturas que permitiram uma estimativa do deslocamento horizontal da ZCC. Baseado neste trabalho propõe-se uma metodologia de mapeamento de zonas de cisalhamento, com destaque das ocorrências de milonitos e ultramilonitos, para diferenciar domínios de maior e menor intensidade de deformação.

CONTEXTO GEOLÓGICO A região considerada (Fig. 2) faz parte de uma ampla zona de interferência tectônica (Trouw et al. 1994, 2000), delineada por estruturas que são o resultado da evolução do segmento meridional da Faixa Brasília (N-S) e por estruturas características da Faixa Ribeira (NE-SW), ambas geradas na Orogenia Brasiliana.

A Faixa Brasília (Almeida 1977) apresenta uma evolução geotectônica prolongada que culminou com um evento colisional no período 650-600 Ma (Dardenne 2000, Pimentel et al. 2000, Valeriano et al.
2004). A Faixa Ribeira (Hasui et al. 1975, Trouw et al. 2000, Heilbron et al. 2004) estruturou-se logo em seguida (590-550 Ma), também em função de um evento colisional.

A estrutura da região enfocada aqui é dominada por um sistema de nappes (Fig. 1). No centro-norte da região aflora a Klippe Carrancas, caracterizada por transporte tectônico de topo para SE. Na parte oeste, ocorrem, da base para o topo, as Nappes Luminárias, São Tomé das Letras e Carmo da Cachoeira, com transporte tectônico para $\mathrm{E}$.

$\mathrm{Na}$ parte sudeste aparecem as Nappes Andrelândia e Liberdade, e a Klippe Aiuruoca. Todas estas nappes registram transporte tectônico de topo para leste relacionado à Faixa Brasília, modificado por cavalgamentos para NNW, atribuídos à evolução da Faixa Ribeira, o que caracteriza a zona de interferência entre as duas faixas. Duas grandes zonas de cisalhamento subverticais destras, de direção NE-SW, cortam as nappes e, por tal razão, devem ser posteriores (Fig. 2). São eles: a Zona de Cisalhamento de Três Corações ao norte, e a Zona de Cisalhamento de Caxambu ao sul.

$\mathrm{O}$ metamorfismo principal, associado à Orogênese Brasiliana, varia desde fácies xisto verde até fácies granulito nas nappes superiores. Ocorrências locais de retroeclogitos, e a presença da associação cianita $+\mathrm{K}$ feldspato, apontam para pressões elevadas. A distribuição deste metamorfismo nas nappes, e a relação de crescimento entre minerais metamórficos e a foliação principal, mostram que este metamorfismo é relacionado à formação das nappes da Faixa Brasília (Trouw et al. 2000).

O crescimento tardio de sillimanita produziu isógradas de sillimanita-in e cianita-out que, numa escala regional, cortam os contatos das nappes. Este crescimento de sillimanita e a parte principal da anatexia foram atribuídos ao metamorfismo relacionado à Faixa Ribeira 


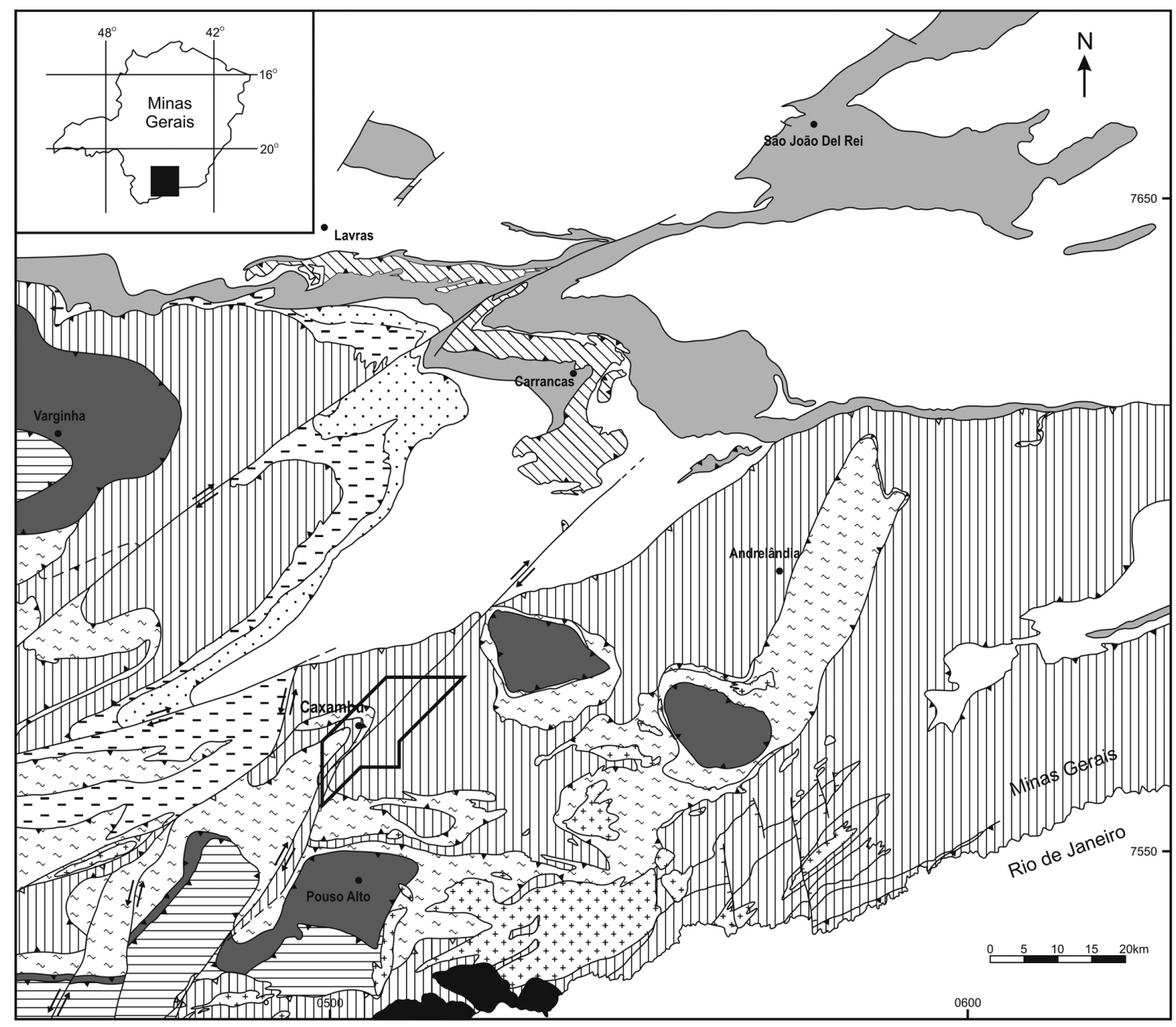

Falha de empurrão e/ou zona cisalhamento de baixo ângulo $\left(\mathrm{D}_{\mathrm{B}}\right)$
Falha reversa e/ou zona de cisalhamento ingreme $\left(D_{R}\right)$
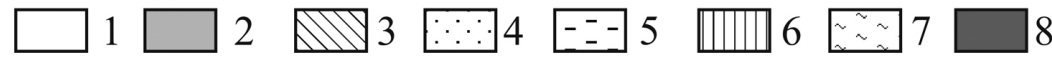

9

Figura 2 - Mapa tectônico regional do Sul de Minas Gerias modificado de Paciullo (1997), Trouw et al. (2000) e Peternel (2005). 1 -Domínio Autóctone (Embasamento); 2 - Domínio Autóctone (Megasseqüência Andrelândia); 3 - Klippe Carrancas; 4 - Nappe Luminárias; 5 - Nappe São Tomé das Letras; 6 - Nappes Natércia, Carmo da Cachoeira e Andrelândia; 7 - Nappes Heliodora e Liberdade; 8 -Nappes Cristina-Pouso Alto, Varginha e Klippe Aiuruoca; 9 - Nappe Socorro-Guaxupé; 10 - Granitóides sin a tardicolisionais, 11 - Maciços alcalinos de Itatiaia e Passa Quatro. O polígono indica a área estudada.

que, em termos gerais, foi de pressão mais baixa.

Ocorrem também espalhados por toda a região, diques de diabásio pós-metamórficos seguindo fraturas e falhas com direção principalmente N-S, que estão possivelmente relacionados à extensão mesozóica que resultou na abertura do Oceano Atlântico Sul.

\section{GEOLOGIA DA ÁREA MAPEADA}

Unidades de mapeamento A nordeste da área mapeada aflora embasamento autóctone, constituído principalmente de ortognaisses paleoproterozóicos (pré-1,8 Ga, Ribeiro et al. 1995). São rochas tonalíticas a granodioríticas que, freqüentemente, mostram um aspecto migmatítico, devido à injeção de veios e diques leucossomáticos, e também à anatexia.
Outros componentes do embasamento são anfibolitos, rochas metaultramáficas, micaxistos, rochas cálcio-silicáticas e quartzitos, em parte ricos em manganês (gonditos). Estes litotipos representam possivelmente restos de uma faixa tipo greenstone belt. Ocorre uma área rica em corpos metaultramáficos a sudeste de Luminárias.

A Megasseqüência Andrelândia (MSA; Paciullo et al. 2000) é uma sucessão metassedimentar neoproterozóica, com rochas metaígneas máficas associadas, que recobrem o embasamento e unidades mesoproterozóicas no domínio autóctone e o embasamento gnáissico nos domínios alóctones. A MSA inclui seis associações de litofácies, agrupadas em cinco unidades de mapeamento (Paciullo et al. 2000): 
$\mathrm{Na}_{1+2}$ - Paragnaisses bandados com intercalações de anfibolitos e metaultramafitos $\left(\mathrm{Na}_{1}\right)$, e de quartzitos, filitos, xistos e anfibolitos $\left(\mathrm{Na}_{2}\right)$, podendo ainda ser delimitadas áreas de quartzito $\left(\mathrm{Na}_{1+2 \mathrm{q}}\right)$;

$\mathrm{Na}_{3}$ - Quartzitos e quartzo-muscovita xistos;

$\mathrm{Na}_{4}-$ Filitos e xistos cinza grafitosos e quartzíticos com intercalações de quartzitos;

$\mathrm{Na}_{5}$ - Biotita xisto/gnaisse feldspático e granatífero;

$\mathrm{Na}_{6}-$ Xistos e paragnaisses variados, ricos em micas, granadas, cianita e/ou sillimanita, com intercalações de quartzito, anfibolito e rochas cálcio-silicáticas. Esta unidade pode ocorrer na fácies granulito $\left(\mathrm{Na}_{6 \mathrm{~g}}\right)$, identificada pela associação cianita $+\mathrm{K}$-feldspato sem muscovita.

Estruturas Como mencionado acima, a região de Caxambu encontra-se inserida na zona de interferência entre as faixas móveis Brasília e Ribeira. Nesta zona foram identificadas duas fases deformacionais regionais (Peternel et al. 2005):

$\mathrm{D}_{\mathrm{B}}$ - Esta fase gerou a foliação principal da área associada a formação de nappes em um regime compressional E-W com direção de transporte tectônico topo para E. Embora em áreas adjacentes esta fase possa ser subdividida em duas por critérios de superposição, na área mapeada não foi possível fazer esta subdivisão. Devido a isso, as fases são consideradas progressivas e a xistosidade principal é referida como $\mathrm{S}_{\mathrm{B}}$. Esta xistosidade com lineação de estiramento associada, foi gerada pelo tectonismo relacionado à Faixa Brasília.

$D_{R}-A$ foliação $S_{B}$ foi dobrada e modificada pelos esforços relacionados à colisão que gerou a Faixa Ribeira com vergência para NW, gerando dobras abertas a fechadas e zonas de cisalhamento associadas. Entre estas zonas destacam-se as subverticais de direção NE-SW com movimento principalmente destro; a ZCC é uma destas zonas de cisalhamento.

A estrutura principal na área mapeada é uma xistosidade bem desenvolvida, $\mathrm{S}_{\mathrm{B}}$, paralela aos contatos litológicos e aos contatos entre as nappes. Ocorrem dobras fechadas a isoclinais associadas, com eixos paralelos a uma lineação de estiramento. A maior parte da área está situada na Nappe Andrelândia, com duas escamas tectônicas da Nappe Liberdade superpostas (Figs. 2, 3).

$S_{B}$ esta deformada por $D_{R}$, fazendo com que os contatos entre as unidades tenham suas superfícies dobradas por "arrasto" da Zona de Cisalhamento Caxambu, nas proximidades da mesma.

Os contatos entre as nappes estão definidos por truncamentos, repetições estratigráficas e pela presença de rochas do embasamento sobre a MSA. Milonitos relacionados a estes empurrões não ocorrem freqüentemente, pois durante o deslocamento das nappes as condições metamórficas promoveram ampla recristalização. Em alguns pontos fora da ZCC foram encontrados indicadores cinemáticos, os quais foram interpretados como tendo sua formação associada ao deslocamento das nappes.
De uma forma geral as foliações relacionadas à ZCC foram chamadas de $S_{R}$. As demais medidas, fora da $\mathrm{ZCC}$ foram interpretadas como $\mathrm{S}_{\mathrm{B}}$. O mesmo se deu para as lineações (Fig. 3).

Analisando as estruturas $\mathrm{D}_{\mathrm{B}}$ de uma forma geral, observam-se planos de foliação com mergulho para SSE, tendo valor médio 154/52 (Fig. 4a). As lineações têm direção ENE-WSW, com valor médio 067/03 (Fig. 4b), corroborando o transporte tectônico relacionado à Faixa Brasília para E de uma forma geral. Este transporte tectônico é também reforçado pela presença de lentes assimétricas de quartzo com movimento sinistral que, revertido para a foliação com mergulho mais suave, indicaria um movimento de topo para ENE.

$\mathrm{Na}$ unidade $\mathrm{Na}_{1+2}$ dobras desde abertas a isoclinais, com eixos em torno de 045/16 e planos axiais em torno de $135 / 65$, foram interpretadas como estruturas associadas à fase $\mathrm{D}_{\mathrm{B}}$. Também no biotita gnaisse bandado, observou-se dobras semelhantes, com eixo 040/00 e plano axial $125 / 60$, igualmente interpretadas como $\mathrm{D}_{\mathrm{B}}$. Pontualmente ocorrem pegmatitos deformados, intrusivos na unidade $\mathrm{Na}_{1+2}$, mostrando um movimento cisalhante destro, indicando um movimento de topo para NW. Associado a este mesmo cisalhamento observouse truncamento de camadas por falhas de baixo ângulo Estas estruturas foram associadas a um transporte tectônico relacionado à Faixa Ribeira.

\section{A ZONA DE CISALHAMENTO CAXAMBU}

Características gerais Resultados preliminares do mesmo grupo de estudo foram comunicados na forma de um resumo (Trouw et al. 2003), sendo que a seguir são apresentados dados mais detalhados.

Baseado principalmente nos aspectos microscópicos foi delimitada em mapa a área de influência da ZCC, ou seja, foi marcada a região onde ocorrem milonitos e protomilonitos gerados por esforços cisalhantes. Desta forma, propõe-se um método de exposição de zonas de cisalhamento em mapa, mostrando as diferenças de intensidade de deformação observada nos diferentes litotipos mapeados (Fig. 3). As ocorrências e o tipo de rocha milonítica existente também são identificados no mapa. No mesmo mapa foram também marcados os indicadores cinemáticos com o sentido de movimento. Indicadores cinemáticos aparentes vistos em afloramento nem sempre foram confirmados pelo estudo microtectônico das lâminas. Nestes casos considerou-se principalmente a análise microscópica.

Com base na orientação e ocorrência da foliação milonítica, foi possível identificar uma área de concentração da deformação $\mathrm{D}_{\mathrm{R}}$, relacionada à ZCC. Esta área é marcada pela orientação preferencial dos planos de foliação $S_{R}$ em torno de 132/73 e lineações $L_{R}$ com atitude média 042/04 (Fig. 4).

Foram identificados quinze afloramentos com indicadores cinemáticos (Fig. 3). Onze indicam movimento destro, sendo que seis destes não deixam sombra de dúvida sobre a sua interpretação. Os quatro indicadores restantes indicam movimento sinistral, porém com menos nitidez que os seis destros. Em uma lâmina 


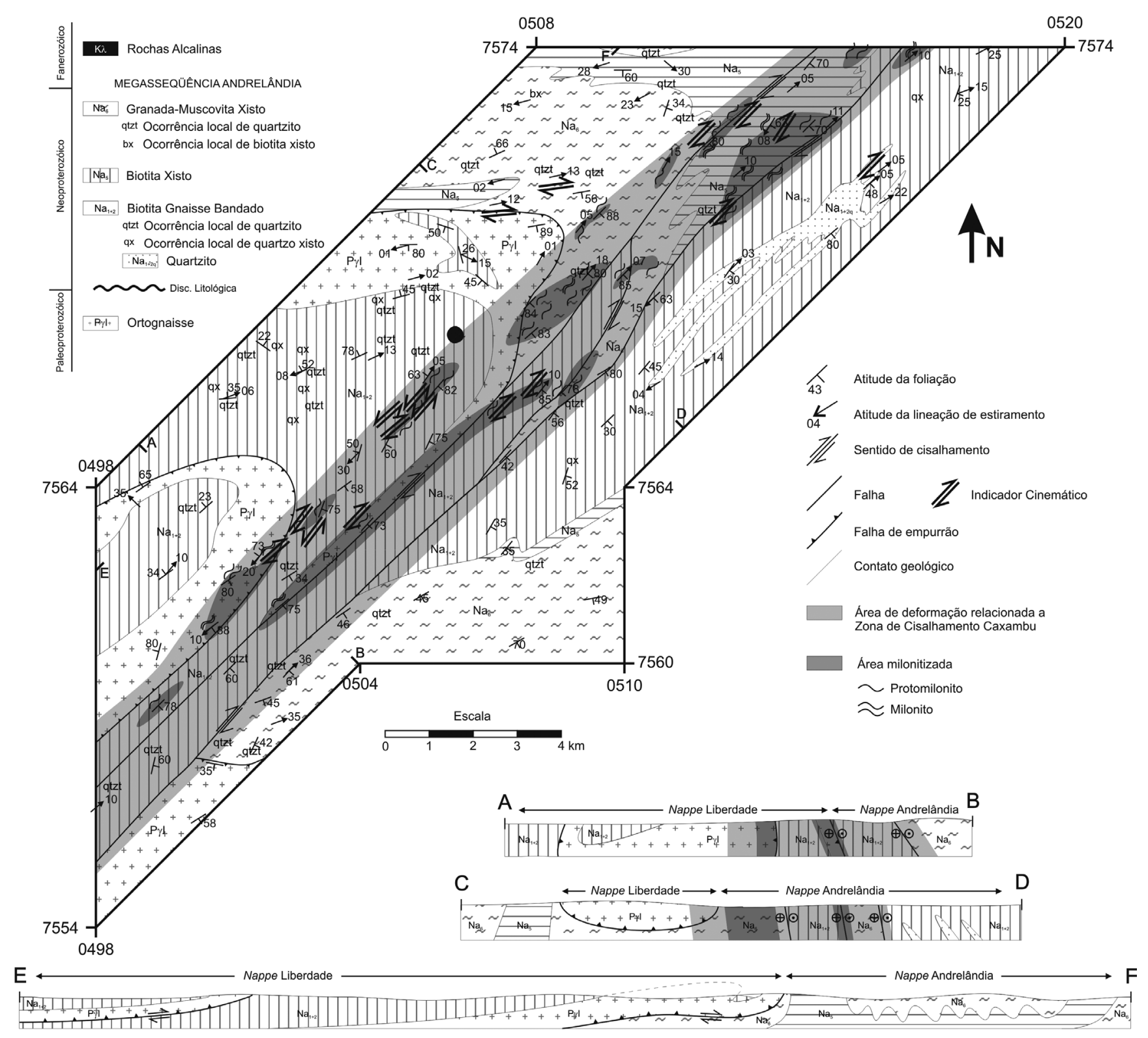

Figura 3 - Mapa geológico de um segmento da Zona de Cisalhamento Caxambu mostrando as diferentes unidades de mapeamento e a variação da forma de atuação da deformação. Seções geológicas possuem exagero de $1,5 X$.

foram observadas estruturas que sugerem a sobreposição de movimento destro sobre movimento sinistro. A interpretação deste conjunto de estruturas não é totalmente clara neste momento. Podem ser relacionadas a dobramentos da superfície de cisalhamento com eixo paralelo às direções de movimento (Goscombe \& Trouw 1999), ou a uma possível reativação da zona de cisalhamento, que poderia ter sido sinistra em uma fase inicial e destra em um estágio posterior.

Através da análise do deslocamento dos contatos entre as unidades de uma forma geral, concluiu-se que a ZCC inclui duas subzonas paralelas principais, de movimento destro, ao longo das quais a maior parte da deformação está concentrada. Ocorre também, na parte central da área, outra zona ligando as duas supracitadas, limitando as unidades $\mathrm{Na}_{1+2}$ e $\mathrm{Na}_{6}$ (Fig. 3).

Devido à escassez de afloramentos não foi pos- sível calcular com precisão o deslocamento de cada subzona. Porém, levando-se em conta o contato de empurrão entre a unidade $\mathrm{PГI} \mathrm{e} \mathrm{Na}_{6}$ na parte sul e central da área, inferiu-se um rejeito aparente horizontal da ZCC no segmento estudado em torno de $14,5 \mathrm{~km}$. Utilizando este deslocamento e a largura da zona $(\sim 2$ $\mathrm{km}$ ), pode-se calcular o valor do componente $\gamma$ de cisalhamento simples (Ramsey 1967, Cap. 3), resultando um valor igual a sete.

Trouw et al. (2003a) reportaram deslocamentos de 17, 20, 22, 12 e $20 \mathrm{~km}$, baseados em vários contatos deslocados ao longo desta zona de cisalhamento a nordeste da área estudada. A média destes deslocamentos é $17,6 \mathrm{~km}$, resultando um valor de $\gamma$ igual a nove. Este valor está na mesma ordem de grandeza do valor obtido neste trabalho. Um deslocamento similar de aproximadamente $11 \mathrm{~km}$ foi estimado para a Zona de Cisalha- 

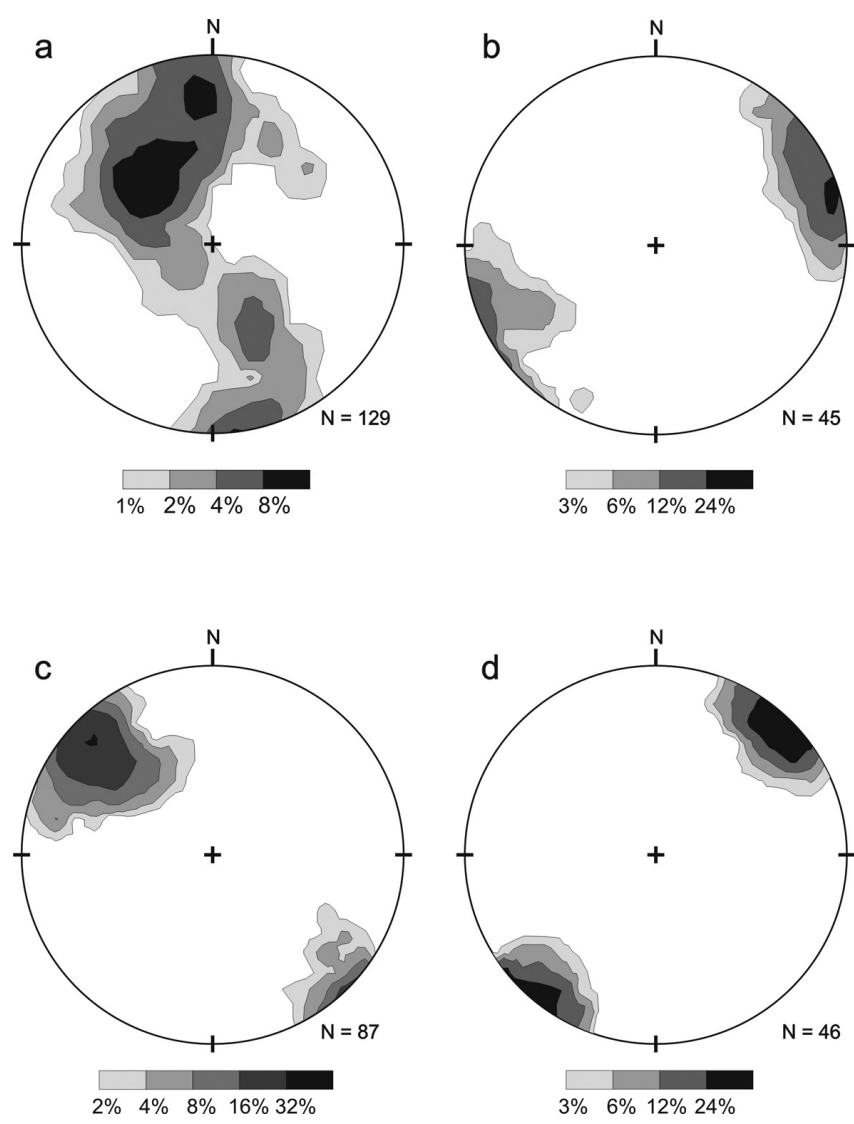

Figura 4 - Estereogramas (rede Schmidt-Lambert, hem. inf.).

a: Foliação $S_{B}$, atitude média $=154 / 52,129$ medidas; b: Lineação $L_{B}$, atitude média $=067 / 03,45$ medidas; $c$ : Foliação $S_{R}$, atitude média $=132 / 73,87$ medidas; $d$ : Lineação $L_{R}$, atitude média $=042 / 04,46$ medidas.

mento de Três Corações (Fig. 2) por Peternel (2000). A partir destes dados, conclui-se que estas zonas de cisalhamento, tem deslocamento entre 7 e $22 \mathrm{~km}$.

Aspectos da deformação na ZCC A Zona de Cisalhamento Caxambu é caracterizada por uma deformação dúctil-rúptil evidenciada desde a escala microscópica até macroscópica.

Foram observados minerais como muscovita, estaurolita ou cianita deformados assimetricamente em forma de losango ou de "peixe" (mica fish, staurolite fish e kyanite fish). Estes indicam um sentido de cisalhamento pelo ângulo entre o eixo maior do mineral e o plano da foliação (Figs. 5a,b).

Microfalhas ocorrem localmente indicando o sentido de cisalhamento pelo seu deslocamento. Normalmente afetam minerais de tamanho relativamente grande, como o plagioclásio e a cianita (Figs. 5c,d). Podem ocorrer também na forma de microzonas de cisalhamento. Observou-se em menor escala imbricação de cristais, além de microfalhas sintéticas e antitéticas.

Estruturas S-C ocorrem freqüentemente nas rochas miloníticas. Planos de foliação nas áreas ricas em quartzo, com orientação em um pequeno ângulo com a foliação milonítica principal, também ocorre como indicador cinemático; esta estrutura é chamada foliação oblíqua (Passchier \& Trouw 2005). Ocorre normalmente pela recristalização do quartzo orientada obliquamente à foliação milonítica. O sentido de cisalhamento pode ser determinado pelo ângulo entre a foliação principal e a foliação oblíqua, que varia normalmente entre 20 e $40^{\circ}$.

Outro indicador cinemático observado é constituído pelas bandas de cisalhamento (shear bands), caracterizadas por pequenas zonas de cisalhamento oblíquas à foliação milonítica geral, gerando um aspecto semelhante à foliação oblíqua. Pode ser dividido em dois tipos principais: $\mathrm{C}$ e C', onde C' representa bandas de cisalhamento oblíquas à zona de cisalhamento (Passchier \& Trouw 2005). Este é o tipo mais freqüentemente observado na área de estudo. As bandas de cisalhamento $\mathrm{C}$ são paralelas à zona de cisalhamento. $\mathrm{O}$ sentido de cisalhamento pode ser determinado pelo mesmo princípio da foliação oblíqua (Figs. 5e,f).

Em determinados porfiroclastos ocorre um "manto" recristalizado, de granulação fina, que tende a deformar muito mais que o núcleo. Nestes casos é possível determinar o sentido de movimento a partir da assimetria do manto em relação ao plano da foliação. $\mathrm{Na}$ área são comuns porfiroclastos de feldspato do tipo $\sigma$ (Passchier \& Simpson 1986), às vezes com outros minerais, como mica, no manto.

Influência dos diferentes litotipos na ZCC O ortognaisse é provavelmente o litotipo mais resistente à deformação $\mathrm{D}_{\mathrm{B}}$. Onde ocorre milonitizado, ele apresenta indicadores cinemáticos como feldspato potássico manteado em um padrão do tipo $\sigma$. Entretanto, poucos feldspatos observados em afloramentos mostram uma assimetria clara; assim, não é possível ter uma informação conclusiva do sentido de cisalhamento somente com dados desta unidade. Em lâmina delgada observase de uma forma geral a recristalização do quartzo e a fragmentação dos feldspatos, evidenciando um caráter mais rúptil da deformação. Em algumas lâminas ocorrem plagioclásios parcialmente dobrados (Fig. 6c).

A unidade $\mathrm{Na}_{1+2}$ dentro da ZCC se apresenta deformada, apresentando dobramento isoclinal (Fig. 6a) e ocorrências de milonitos evidenciados pela recristalização do quartzo e intensificação da foliação, normalmente marcada pelo alinhamento da biotita. É comum observar indicadores cinemáticos microscópicos. Estruturas S-C' são observadas na forma de bandas de cisalhamento normalmente compostas por biotita e muscovita. Em maior quantidade ocorrem os minerais alongados assimetricamente. São principalmente muscovitas em camadas quartzíticas. Esporadicamente este tipo de estrutura também ocorre em estaurolitas.

$\mathrm{O}$ biotita xisto/gnaisse $\left(\mathrm{Na}_{5}\right)$ é a unidade que mais evidencia a deformação gerada pela Zona de Cisalhamento Caxambu $\left(\mathrm{D}_{\mathrm{R}}\right)$, tendo ocorrências freqüentes de rochas milonitizadas. Em afloramento, o aspecto principal é a foliação milonítica. Em uma pedreira abandonada próximo à cidade de Caxambu ocorrem zonas de cisalhamento de escala centimétrica e estrutu- 

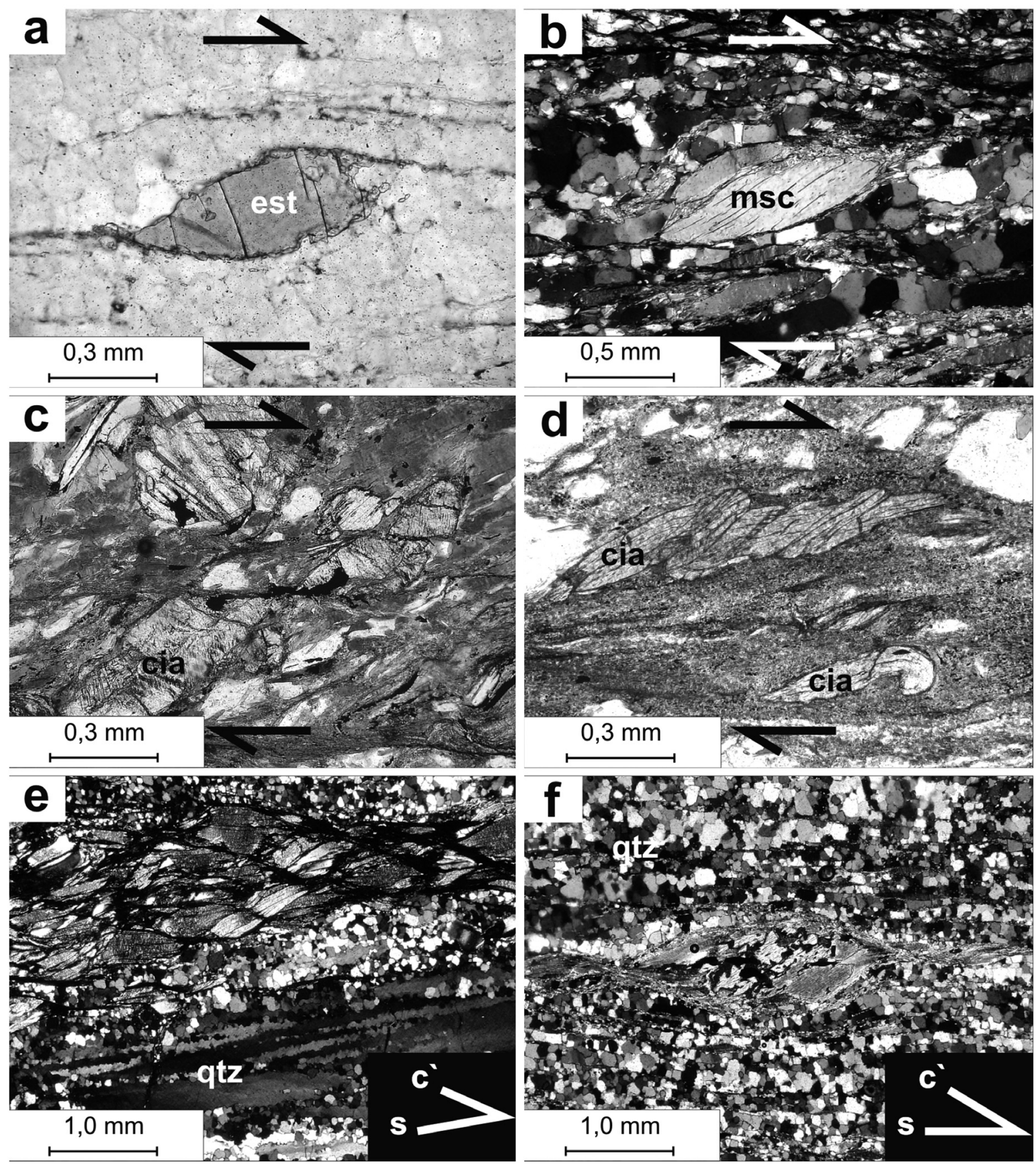

Figura 5 - Indicadores cinemáticos: a - Fotomicrografia de estaurolita alongada assimetricamente (staurolite fish), indicando cisalhamento destro em quartzito da unidade $\mathrm{Na}_{1_{+2}}$. $b$-Fotomicrografia de muscovita alongada assimetricamente (mica fish) indicando cisalhamento destro em biotita gnaisse quartzítico milonítico. c - Fotomicrografia de cianita falhada ao longo de planos de cisalhamento paralelos à foliação no biotita xisto milonitizado indicando cisalhamento destro; note o mineral opaco desmembrado e estirado nos dois lados da falha no meio da fotomicrografia. d-Fotomicrografia evidenciando o aspecto dúctil da deformação através de dobras e alongamentos assimétricos de cianitas, indicando um cisalhamento destro, unidade $\mathrm{Na}_{5^{\prime}}$ e-Fotomicrografia de granada-muscovita xisto com nível micáceo com estruturas $S$-C' e nível quartzítico com quartzo parcialmente recristalizado evidenciado pelas fitas remanescentes dos grãos velhos. $f$ - Fotomicrografia de estruturas $S$-C' na forma de bandas de cisalhamento indicando cisalhamento destro em quartzito da unidade $\mathrm{Na}_{1+2}$.

ras S-C. Nas lâminas delgadas observa-se em geral uma foliação anastomosada. Níveis de intensidade de milonitização diferentes são comuns e podem ter espessuras e continuidades variadas. As cianitas constituem bons indicadores do sentido de movimento podendo se apresentar deformadas com kink-bands, dobras ou ainda falhadas (Fig. 6d), evidenciando o aspecto dúctil-rúptil da ZCC. Entre outros indicadores cinemáticos pode- 

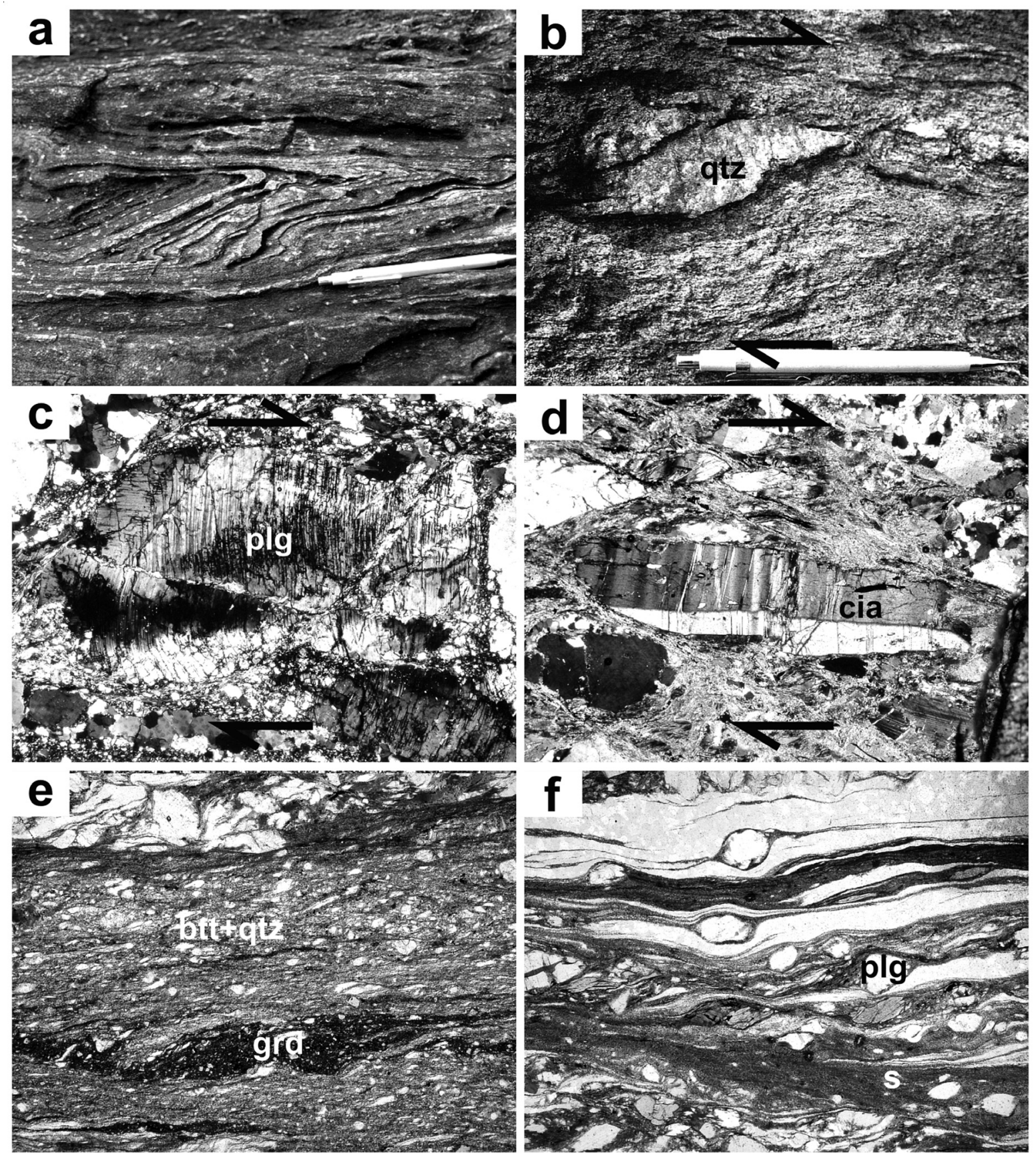

Figura 6 - Aspectos deformacionais da Zona de Cisalhamento Caxambu. a - Fotografia de dobras fechadas a isoclinais $\left(D_{R}\right)$ na unidade $N a_{1+2}$. $b$ - Fotografia mostrando uma lente assimétrica de quartzo indicando um sentido de cisalhamento destro ligado a deformações anteriores à ZCC. c- Fotomicrografia de ortognaisse milonítico, com um plagioclásio deformado tendo sua geminação polissintética dobrada, caracterizando o aspecto dúctil-rúptil da deformação. d-Fotomicrografia de cianita com kink-bands ortogonais ao seu eixo maior, ressaltando a intensidade da deformação, unidade $\mathrm{Na}_{5}$. $\mathrm{e}$ A mancha escura na parte inferior da fotomicrografia é uma granada extremamente deformada por cataclase, unidade $\mathrm{Na}_{5^{\circ}} f$ - Fotomicrografia do aspecto milonítico geral do biotita xisto ( $\mathrm{Na}$ ), tendo um plagioclásio com sombra de pressão assimétrica do tipo $\sigma$ na parte superior, indicando um cisalhamento destro.

se destacar: veios de quartzo em forma de sigmóide (Fig. 6b), dos quais pode-se inferir o sentido de cisalhamento pela sua assimetria, similarmente aos mica fish; foliação oblíqua, normalmente gerada pela orientação dos cristais de quartzo recristalizados; plagioclásios manteados com estruturas de deformação do tipo $\sigma$ (Fig. 6f) e granadas com estruturas de deformação do tipo $\delta$. A granada se apresenta com diferentes formas devido à diferença de intensidade da deformação $D_{B}$. Devido à sua resistência relativa ela pode ter sua forma externa inalterada ou ter sua forma original totalmente desconfigurada devido à deformação por catáclase pro- 
gressiva, fazendo com que a mesma assuma um aspecto semelhante ao da matriz (Fig. 6e).

A análise deformacional e cinemática da unidade $\mathrm{Na}_{6}$ é restrita devido à pequena quantidade de afloramentos de rocha sã na área de influência da ZCC, fazendo assim com que existam poucas lâminas para se obter dados microscópicos mais conclusivos. Foram observadas micas alongadas assimetricamente e estruturas S-C na forma de bandas de cisalhamento em níveis de concentração de micas. O quartzo esta parcialmente recristalizado, podendo ocorrer "fitas" com subgrãos.

Metamorfismo A partir das associações de minerais metamórficos cianita+sillimanita+estaurolita+clorita pode-se concluir que o metamorfismo principal atingiu o início da fácies anfibolito. Supondo que houve equilíbrio entre estes minerais no auge de metamorfismo, infere-se temperaturas entre 520 e $560{ }^{\circ} \mathrm{C}$ pela coexistência de estaurolita e clorita. As condições de pressão ficariam próximas a 4 kbar devido à coexistência de sillimanita e cianita.

Entretanto, é mais provável que a cianita e sillimanita sejam gerados em momentos diferentes na evolução P-T-t. Supondo isso, é provável que as associações com cianita se formassem com pressões acima de 4 kbar e as com sillimanita com pressões abaixo ou próximo de 4 kbar. Também é possível que a clorita se formasse secundariamente após o auge do metamorfismo. Nesse caso a presença de estaurolita sem clorita poderia refletir uma temperatura de até $680{ }^{\circ} \mathrm{C}$.

A existência de oligoclásio em ocorrências locais de anfibolito na unidade $\left(\mathrm{Na}_{1+2}\right)$ também indica que o metamorfismo alcançou a fácies anfibolito.

A ocorrência de quartzo, biotita e plagioclásio recristalizado dentro da zona de cisalhamento, assim como o deslocamento regional de isogradas metamórficas em escala regional descrito por Peternel et al. (2005), corroboram a hipótese de que a zona de cisalhamento se implementou após o auge do metamorfismo da Faixa Ribeira nesta região.

Reativação da ZCC Foram observadas na área de deformação relacionada à Zona de Cisalhamento Caxambu planos com espelhos de falha, de escalas centimétrica a decimétrica, com direção NE-SW, paralelos à ZCC. Estas falhas são interpretadas como reativações cretáceas ou cenozóicas da ZCC, que podem ter relação com um período do Cretáceo Superior até o Recente caracterizado por vários eventos tectônico-magmáticos na região Sudeste do Brasil, tanto no mar como em terra. Estes eventos incluem intrusões de rochas alcalinas datadas desde 90 a $50 \mathrm{Ma}$, entre elas o plug de Caxam$b u$ e a formação de várias bacias tipo rifte continentais próximas a costa dos Estados de São Paulo e Rio de Janeiro.

A ocorrência do plug de rochas alcalinas (K $\Lambda$ ) no limite da zona de cisalhamento sugere que esta intrusão seguiu o plano anisotrópico implementado pela ZCC. Isso significaria que mesmo muito depois da sua atividade no Pré-Cambriano a ZCC pode ser sido uti- lizada como uma estrutura planar de intrusão preferencial.

CONCLUSÕES O estudo detalhado da ZCC revelou com clareza a natureza de um tipo de lineamento que foi gerado no final do Pré-Cambriano. Foram reconhecidos dois conjuntos principais de estruturas: $\mathrm{D}_{\mathrm{B}}$, progressiva, é responsável pela geração da foliação principal da área associada à formação das nappes, em um regime compressivo E-W com direção de transporte tectônico para E. $\mathrm{D}_{\mathrm{R}}$, posteriormente, gerou uma compressão NW-SE resultando em estruturas com vergência para NW. No final desta fase ocorreu uma rotação das direções principais de compressão de novo para E-W gerando entre outras estruturas a Zona de Cisalhamento Caxambu, em condições dúcteis-rúpteis.

A ZCC é uma zona de cisalhamento SW-NE, subvertical, com caráter predominante dúctil. Possui comprimento de no mínimo $100 \mathrm{~km}$ e largura em torno de $2,5 \mathrm{~km}$ e um deslocamento horizontal destro estimado em 14,5 km na área mapeada, e uma média de 17,6 $\mathrm{km}$ numa área maior. $\mathrm{O}$ valor médio para $\gamma$ de cisalhamento simples para a zona como um todo foi estimado em sete. Embora os indicadores destros sejam predominantes ao longo da zona, indicadores sinistros também foram observados. A interpretação mais provável é que a zona iniciou sua atividade com movimento sinistro, sendo posteriormente reativado com movimento destro.

Devido a sua orientação e sentido de movimento, conclui-se que a ZCC é tardia em relação ao conjunto principal de estruturas relacionadas à Faixa Ribeira. Desta forma, pode-se afirmar que a mesma não possui relação com o sistema de nappes gerado pela deformação relacionada à Faixa Brasília. Zonas de Cisalhamento a norte da Nappe Socorro inseridos no Cinturão Transcorrente Campo do Meio (Ebert et al. 1996) não são correlacionáveis à ZCC, pois se formaram durante a Deformação Brasília, anterior a gênese da ZCC.

As condições metamórficas durante a milonitização foram estimadas como da parte inicial da fácies anfibolito.

Sua idade é estimada como neoproterozóica a cambriana. Posteriormente foi reativada por falhas provavelmente normais no Cretáceo ou Cenozóico. A ocorrência da unidade $\mathrm{K} \Lambda$ no limite da zona de cisalhamento também é um indício de reativação.

Agradecimentos $\mathrm{O}$ presente estudo foi realizado parcialmente no âmbito de uma monografia de C.C. Trouw, uma dissertação de mestrado de F.F.F Medeiros e uma tese de doutorado de C.C. Trouw, vinculadas ao Departamento de Geologia da UFRJ, ao qual expressamos nossos agradecimentos. C.C. Trouw e F.F.F. Medeiros foram contemplados com bolsas da CAPES e R.A.J. Trouw agradece auxílio do CNPq na forma de uma bolsa de produtividade em pesquisa. Agradecemos os colegas André Ribeiro, Fabio Paciullo e Rodrigo Peternel pela ajuda nas etapas de campo e discussões geológicas. 


\section{Referências}

Almeida F.F.M. 1977. O Cráton do São Francisco. Rev. Bras. Geoc., 7:349-364.

Almeida F.F.M., Hasui Y., Carneiro C.R. 1975. Lineamento de Além Paraíba. Anais da Academia Brasileira de Ciências, 47:575.

Almeida J.C.H. 2000. Zonas de cisalhamento dúctil de alto grau do Médio Vale do Rio Paraíba do Sul. Tese de Doutoramento, Instituto de Geociências e Ciências Exatas, Universidade Estadual Paulista, Rio Claro, SP, 190 p.

Campanha G.A.C. 1981. O Lineamento de Além Paraíba na área de Três Rios (RJ). Rev. Bras. Geoc. 11:159-171.

COMIG 2003. Mapa geológico do estado de Minas Gerais, escala 1:1.000.000.

Dardenne M.A. 2000. The Brasília Fold Belt. In: Cordani U.G., Milani E.J., Thomaz-Filho A., Campos D.A. (eds.) Tectonic evolution of South America, $31^{\text {st }}$ Int. Geol. Congr., Rio de Janeiro, p. 231-263.

Ebert H.D., Chemale F.Jr., Babinski M., Artur A.C., Van Schmus W.R. 1996. Tectonic setting and U/Pb zircon dating of the plutonic Socorro Complex in the Transpressive Rio Paraíba do Sul Shear Belt, SE Brazil. Tectonics., 15-2:688-699.

Goscombe B. \& Trouw R.A.J. 1999. The geometry of folded tectonic shear sense indicators. Journ. Struct. Geol., 21:123-127.

Hasui Y., Carneiro C.D.R, Coimbra, A. M. 1975. The Ribeira Fold Belt. Rev. Bras. Geoc., 5:257-266.

Heilbron M., Pedrosa-Soares A.C., Campos Neto M., Silva L.C., Trouw R.A.J. \& Janasi, V.C. 2004. A Província Mantiqueira: In: Mantesso-Neto V., Bartorelli A., Carneiro C.D.R., Brito Neves B.B. (eds). Geologia do continente sul-americano. Evolução da obra de Fernando Flávio Marques de Almeida, p. 203-234.

Machado R. \& Endo I. 1993a. Estruturas transcorrentes da borda sul do Cráton do São Francisco: uma interpretação. In: SBG, Simpósio sobre o Cráton do São Francisco, 2, Salvador, Anais, p. 263-265.

Machado R. \& Endo I. 1993b. A Megaestrutura em flor positiva do vale do Rio Paraíba do Sul no Rio de Janeiro, e suas implicações tectônicas regionais. In: SBG, Símp. Geol. Sudeste, 3, Rio de Janeiro, Anais, p. 208-213.

Machado R. \& Endo I. 1993c. Cinturão de Cisalhamento Atlântico: um exemplo de tectônica transpressional neoproterozóica. In: SBG, Simpósio Nacional de Estudos Tectônicos, 4, Salvador, Bol. Res., p. 189-191.

Paciullo F.V.P. 1997. A Sequência Deposicional Andrelândia. Tese de Doutoramento, Instituto de Geociências, Universidade Federal do Rio de Janeiro, 245p.

Paciullo F.V.P., Ribeiro A., Andreis R.R., Trouw R.A.J., 2000. The Andrelândia basin, a neoproterozoic intraplate continental margin, southern Brasília Belt, Brazil. Rev. Bras. Geoc. 30:200-202.

Passchier C.W. \& Simpson C. 1986. Porphyroclast systems as kinematic indicators. Journal of Struct. Geol. 8:831844.

Passchier C.W. \& Trouw R.A.J. 2005. Microtectonics, 2nd ed., Germany, Springer-Verlag, 366 p.
Peternel R.M.N. 2000. Evolução estrutural e metamórfica de um sistema de nappes na região de Três Corações, sul de Minas Gerais. Dissertação de Mestrado, Instituto de Geociências, Universidade Federal do Rio de Janeiro, $120 \mathrm{p}$.

Peternel R.M.N. 2005. A zona de superposição entre as Faixas Brasília e Ribeira na região entre Caxambu e Pedralva, sul de Minas Gerais. Tese de Doutoramento, Instituto de Geociências, Universidade Federal do Rio de Janeiro, 250p.

Peternel R.M.N., Trouw R.A.J., Schmitt R.S. 2005. Interferência entre duas faixas móveis neoproterozóicas: o caso das faixas Brasília e Ribeira no Sudeste do Brasil. Rev. Bras. Geoc. 35:297-310.

Pimentel M.M., Fuck R.A., Jost H., Ferreira-Filho C.F., Araújo S.M., 2000. The basement of the Brasília Belt and the Goiás Magmatic Arc. In: Cordani U.G., Milani E.J., Thomaz-Filho A. \& Campos D.A. (eds). Tectonic evolution of South America, $31^{\text {st }}$ Int. Geol. Congr, Rio de Janeiro, p. 195-229.

Ramsey J.G. 1967. Folding and fracturing of rocks., New York, McGraw Hill, 568 p.

Ribeiro A., Andreis R.R., Trouw R.A.J., Paciullo F.V.P., Valença J.G. 1995. Evolução das bacias proterozóicas e o termo-tectonismo brasiliano na margem sul do Cráton do São Francisco. Rev. Bras. Geoc., 25:235-248.

Silva L.C. 2001. Geologia do Estado do Rio de Janeiro: texto explicativo do mapa geológico do Estado do Rio de Janeiro / $2^{\mathrm{a}}$ ed., Brasília, CPRM.

Trouw R.A.J., Peternel R., Medeiros F.F.F., Trouw C.C., Rodrigues L.H.O. 2003. The Neoproterozoic Caxambu Shear Zone, MG. In: SBG, Simp. Nac. Estudos Tectônicos, 9, Boletim de Resumos, p.124-127.

Trouw R.A.J., Heilbron M., Ribeiro A., Paciullo F.V.P., Valeriano C.M., Almeida, J.C.H., Tupinambá M., Andreis R.R., 2000. The Central Segment of the Ribeira Belt. In: Cordani U.G., Milani E.J., Thomaz Filho A., Campos D.A. (eds.) Tectonic evolution of South America. Rio de Janeiro $31^{\text {st }}$ International Geological Congress, p.287310.

Trouw R.A.J., Paciullo F.V.P., Ribeiro A. 1994. A Faixa Alto Rio Grande reinterpretada como zona de interferânecia entre a Faixa Brasília e a Faixa Ribeira. In: SBG, Cong. Bras. Geol., 38, Res. Exp., v.3, p.234-235.

Valeriano C.M., Machado N., Simonetti A., Valladares C.S., Seer H.J., Simões L.S., 2004. U-Pb Geochronology of the southern Brasília Belt (SE Brazil): sedimentary provenance, Neoproterozoic orogeny and assembly of WestGondwana. Precambrian Research, 130:27-55.

Vauchez A., Tommasi A., Egydio-Silva M. 1994. Self-indentation of a heterogeneous continental lithosphere. Geology, 22:967-970.

Manuscrito AE-093/2006 Submetido em 11 de julho de 2007 Aceito em 01 dezembro de 2007 